\title{
Degree-Based Topological Indices ${ }^{\dagger}$
}

Ivan Gutman

\author{
Faculty of Science, University of Kragujevac, P. O. Box 60, 34000 Kragujevac, Serbia \\ Chemistry Department, Faculty of Science, King Abdulaziz University, Jeddah 21589, Saudi Arabia \\ E-mail: gutman@kg.ac.rs
}

RECEIVED MAY 30, 2013; REVISED JULY 1, 2013; ACCEPTED JULY 1, 2013

\begin{abstract}
The degree of a vertex of a molecular graph is the number of first neighbors of this vertex. A large number of molecular-graph-based structure descriptors (topological indices) have been conceived, depending on vertex degrees. We summarize their main properties, and provide a critical comparative study thereof. (doi: 10.5562/cca2294)
\end{abstract}

Keywords: topological index, molecular structure descriptor, vertex-degree-based topological index, molecular graph, chemical graph theory

\section{INTRODUCTION}

According to the IUPAC definition, ${ }^{1}$ a topological index (or molecular structure descriptor) is a numerical value associated with chemical constitution for correlation of chemical structure with various physical properties, chemical reactivity or biological activity. Countless such "structure descriptors" have been and are being proposed so $\mathrm{far}^{2-7}$ in many cases without any examination if these correlate with any of the "various physical properties, chemical reactivity or biological activity". Especially numerous are the molecular-graph-based structure descriptors. To use a mild expression, today we have far too many such descriptors, and there seems to lack a firm criterion to stop or slow down their proliferation.

In order to contribute towards the reduction of the number of molecular-graph-based structure descriptors, and in the same time to single out those that deserve to be used in chemical applications, we have undertaken a comparative testing thereof. ${ }^{8-11}$ In this paper, we first present the most familiar distance-based structure descriptors, and then report results on their comparison. Before this, we need to recall a few concepts from chemical graph theory. ${ }^{12,13}$

Under "molecular graph" we understand a simple graph, representing the carbon-atom skeleton of an organic molecule (usually, of a hydrocarbon). Thus, the vertices of a molecular graph represent the carbon atoms, and its edges the carbon-carbon bonds.

Let $G$ be a molecular graph. Two vertices of $G$, connected by an edge, are said to be "adjacent". If two

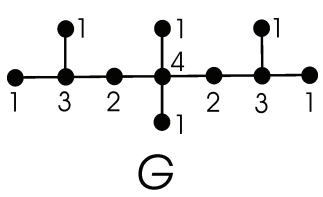

Figure 1. The molecular graph $G$ of 2,4,4,6-tetramethylheptane with its vertex degrees indicated. Thus, $G$ has six vertices of degree 1 (so called "pendent" vertices, representing methyl groups), two vertices of degree 2, two vertices of degree 3 , and one vertex of degree 4 . For obvious chemical reasons, molecular graphs of hydrocarbons cannot possess vertices whose degrees are greater than 4 .

vertices $u$ and $v$ are adjacent, we shall write $u \sim v$. The number of vertices of $G$, adjacent to a given vertex $v$, is the "degree" of this vertex, and will be denoted by $d_{v}(G)$ or, if misunderstanding is not possible, simply by $d_{v}$. The concept of degree in graph theory is closely related (but not identical) to the concept of valence in chemistry. An illustrative example is provided in Figure 1.

\section{SURVEY OF SELECTED DEGREE-BASED TOPOLOGICAL INDICES}

\section{Randić or Connectivity Index}

Historically, the first vertex-degree-based structure descriptors were the graph invariants that nowadays are called Zagreb indices. ${ }^{14,15}$ However, initially these were intended to be used for a completely different purpose

\footnotetext{
$\dagger$ Dedicated to Professor Douglas Jay Klein on the occasion of his $70^{\text {th }}$ birthday.
} 
(see below), and these were included among topological indices much later. The first genuine degree-based topological index was put forward in 1975 by Milan Randić in his seminal paper ${ }^{16}$ "On characterization of molecular branching”. His index was defined as

$$
R=R(G)=\sum_{u \sim v} \frac{1}{\sqrt{d_{u}(G) d_{v}(G)}}
$$

with summation going over all pairs of adjacent vertices of the molecular graph $G$. Randic himself named it "branching index", but soon it was re-named ${ }^{17,18}$ to "connectivity index". Nowadays, most authors refer to it as to the "Randic index".

There is no doubt that the Randic index is the most studied, most often applied, and most popular among all topological indices. Hundreds of papers and a few books ${ }^{18-21}$ are devoted to this structure descriptor. Randić himself wrote two reviews on his index, ${ }^{22,23}$ and there are three more. ${ }^{24-26}$ The suitability of the Randić index for drug design was immediately recognized, ${ }^{15,16}$ and eventually the index was used for this purpose on countless occasion. The physical reason for the success of such a simple graph invariant is still an enigma, although several more-or-less plausible explanations were offered. ${ }^{27-30}$

The Randić index $R$ was invented in 1975. The next twenty years, this graph invariant did not attract any attention of mathematicians, who apparently considered it too simple to deserve examination. Then Pál Erdös, one of the most distinguished mathematicians of his time, together with Béla Bollobás envisaged the beautiful but difficult mathematics hidden in Randić index, and published their first paper ${ }^{31}$ on this matter, soon followed by another. ${ }^{32}$ (The paper $^{31}$ appeared in 1998, but was circulating among mathematicians already a few years earlier.) When the mathematical and mathematico-chemical communities recognized that the Randić index is worth studying, a flood of results and publications started, showing no sign of attenuation. The interested reader should consult the books, ${ }^{20,21}$ the recent papers, ${ }^{33-36}$ and the references cited therein. A particularly interesting result is ${ }^{37}$

$$
R(G)=\frac{n}{2}-\frac{1}{2} \sum_{1 \leq i<j \leq n-1}\left(\frac{1}{\sqrt{i}}-\frac{1}{\sqrt{j}}\right)^{2} m_{i j}
$$

where $G$ stands for any graph with $n$ vertices, in which there are $m_{i j}$ edges connecting a vertex of degree $i$ with a vertex of degree $j$. An immediate consequence of the identity (2) is that $n / 2$ is the maximal value of the Randić index of any $n$-vertex graph, achieved by graphs each of whose components is a regular graph (of degree greater than zero). Many other properties of the Randić index are easily deduced from Equation (2), for instance that the star and the path are the trees with minimal and maximal $R$-value. ${ }^{38}$

A recently discovered unexpected mathematical feature of the Randic index is its connection with the normalized Laplacian matrix. ${ }^{39-41}$

\section{Zagreb Indices}

Analyzing the structure-dependency of total $\pi$-electron energy, ${ }^{14}$ an approximate formula was obtained in which terms of the form

$$
\begin{gathered}
M_{1}(G)=\sum_{v} d_{v}(G)^{2} \\
M_{2}(G)=\sum_{u \sim v} d_{u}(G) d_{v}(G)
\end{gathered}
$$

occured. It was immediately recognized that these terms increase with the increasing extent of branching of the carbon-atom skeleton, ${ }^{14,15}$ i.e., that these provide quantitative measures of molecular branching. Ten years later, in a review article, ${ }^{42}$ Balaban et al. included $M_{1}$ and $M_{2}$ among topological indices and named them "Zagreb group indices".

With regard to this, some explanation is needed. First, in the early 1980 s, only a handful of topological indices were known, and the authors of the review ${ }^{42}$ needed as many of them as possible. Second, in that time both authors of the paper ${ }^{14}$ were members of the Theoretical Chemistry Group of the "Ruđer Bošković" Institute in Zagreb. Balaban et al. probably wanted to avoid calling $M_{1}$ and $M_{2}$ by the name(s) of the discoverers, which otherwise is the usual practice (recall the Wiener, Hosoya, Balaban, Merrifield-Simmons, Narumi-Katayama indices, in addition to the Randić index).

The name "Zagreb group index" was soon abbreviated to "Zagreb index", and nowadays $M_{1}$ is referred to as the "first Zagreb index" whereas $M_{2}$ as the "second Zagreb index".

For quite some time it was not recognized that the sum of squares of vertex degrees, i.e., what we call first Zagreb index, was independently examined in the mathematical literature. ${ }^{43-48}$ Results obtained in the theory of Zagreb indices are summarized in the reviews. ${ }^{49-52}$ The chemical aspects of $M_{1}$ and $M_{2}$ are outlined in the reviews. ${ }^{49,52}$ The survey ${ }^{50}$ complements the review, ${ }^{49}$ by pointing out the mathematical connections of $M_{1}$, whereas the survey ${ }^{51}$ does the same for $M_{2}$.

In sharp contrast to the Randic index, the two Zagreb indices have found almost no applications for modeling physico-chemical, pharmacologic, or any other properties of organic molecules. The isomerdiscriminating power of Zagreb indices (which is rather low) was investigated, ${ }^{53-55}$ and these indices were proposed to measure molecular complexity. ${ }^{56}$ 
In spite of lack of practical chemical applicability, scores of papers appeared (and are still appearing) in the mathematico-chemical literature, in which a variety of mathematical properties of $M_{1}$ and $M_{2}$ are established. Of these, we first mention the remarkable identity ${ }^{57}$

$$
M_{1}(G)=\sum_{u \sim v}\left[d_{u}(G)+d_{v}(G)\right]
$$

which, compared with Equation (4), hints towards a deeper-lying relation between the two Zagreb indices. A more general version of Equation (5) was also established. ${ }^{58}$

The majority of papers dealing with Zagreb indices reports lower and upper bounds for $M_{1}$ and/or $M_{2}$, or determine the graphs for which $M_{1}$ and/or $M_{2}$ assume extremal (minimal or maximal) values. Usually, results of this kind are established for some specified class of (molecular) graphs. We quote here only some most recent works of this kind, ${ }^{59-65}$ in which references to earlier studies can be found. Numerous papers on Zagreb indices are appearing also in mathematical journals; see the recent articles ${ }^{66-70}$ and the references cited therein.

Pierre Hansen noticed that for numerous graphs with $n$ vertices and $m$ edges, the inequality

$$
\frac{M_{1}(G)}{n} \leq \frac{M_{2}(G)}{m}
$$

is satisfied. He conjectured that this inequality holds for all graphs. Damir Vukičević soon found counterexamples for (6), showing that in the general case Hansen's conjecture was false, but that (6) holds for all molecular graphs. ${ }^{71}$ Unexpectedly, research along these lines did not stop, but a long series of papers resulted. ${ }^{72-85}$ The relation (6) is nowadays referred to as the "Zagreb index inequality". For more details see the reviews. ${ }^{86,87}$

\section{Narumi-Katayama and Multiplicative Zagreb Indices}

Narumi and Katayama ${ }^{88}$ considered the product of vertex degrees

$$
N K(G)=\prod_{v} d_{v}(G)
$$

but this structure descriptor attracted only a limited attention. ${ }^{89-92}$ Recently, however, following a suggestion by Todeschini and Consonni, ${ }^{93}$ the multiplicative versions of the Zagreb indices entered the scene. Bearing in mind Equations (3-5), one arrives at

$$
\begin{gathered}
\Pi_{1}(G)=\prod_{v} d_{v}(G)^{2} \\
\Pi_{2}(G)=\prod_{u \sim v} d_{u}(G) d_{v}(G) \\
\Pi_{1}^{*}(G)=\prod_{u \sim v}\left[d_{u}(G)+d_{v}(G)\right]
\end{gathered}
$$

which are referred to as the "first multiplicative Zagreb index" index" $\left(\Pi_{2}\right)$, and the "modified first multiplicative Zagreb index" ${ }^{\prime \prime 4}\left(\prod_{1}^{*}\right)$. Evidently, the Narumi-Katayama index and the first multiplicative Zagreb index are simply related as

$$
\Pi_{1}(G)=N K(G)^{2} .
$$

The few papers, ${ }^{90,21,94-103}$ published so far on multiplicative Zagreb indices, determine the graphs (from various classes) for which $\Pi_{1}, \Pi_{1}^{*}$ and/or $\Pi_{2}$ assume extremal (minimal or maximal) values, or establish inequalities between them.

\section{Atom-bond Connectivity Index}

Let $e$ be the edge of the molecular graph $G$, connecting the vertices $u$ and $v$. Then the term $d_{u} d_{v}$ in the definition of the Randic index, Equation (1), is the product of degrees of the end-vertices of the edge $e$. The degree of this edge, i.e., the number of edges adjacent to $e$ is equal to $d_{u}+d_{v}-2$. In order to take also this information into account, Ernesto Estrada ${ }^{104}$ conceived a new topological index, that is an amended version of Equation (1). $\mathrm{He}$ named it "atom-bond connectivity index" which is conveniently abbreviated by $A B C$. It is defined as

$$
A B C(G)=\sum_{u \sim v} \sqrt{\frac{d_{u}(G)+d_{v}(G)-2}{d_{u}(G) d_{v}(G)}}
$$

a formula that should be compared with Equation (1). It was shown ${ }^{104-106}$ that the $A B C$-index is excellently correlated with the thermodynamic properties of alkanes, especially with their heats of formation. A theoretical explanation for this fortunate property of the atom-bond connectivity index was offered. ${ }^{105}$ By this, $A B C$ happens to be the only topological index for which a theoretical, quantum-theory-based, foundation and justification has been found.

When a new topological index is introduced, one of the first questions that need to be answered is for which (molecular) graphs this index assumes minimal and maximal values. It was relatively easy to prove that among graphs with a fixed number of vertices, the complete graph has the greatest $A B C$ index, ${ }^{107,108}$ and that the tree with greatest $A B C$-value is the star. ${ }^{109}$ The connected graph with minimal $A B C$-index must be a tree, ${ }^{108}$ but - surprisingly - the structure of this tree was (and still is) difficult to determine. The seemingly benign problem of characterizing the $n$-vertex tree (or trees) with minimal $A B C$-index became a much-studied topic. ${ }^{10-118}$ In spite of extensive computer-aided searches, ${ }^{110-112,117}$ all the conjectured minimal- $A B C$ trees were, by means of counterexamples, shown to be incor- 
rect. $^{114,115}$ Details of this " $A B C$ index conundrum" can be found in the survey. ${ }^{116}$

A number of other properties of the atom-bond connectivity index (mainly bounds and characterization of the extremal members of various classes of graphs) have been recently established. ${ }^{119-133}$

\section{Augmented Zagreb Index}

Motivated by the success of the $A B C$ index, Furtula et $a l .{ }^{134}$ put forward its modified version, that they somewhat inadequately named "augmented Zagreb index". It is defined as

$$
A Z I(G)=\sum_{u \sim v}\left(\frac{d_{u}(G) d_{v}(G)}{d_{u}(G)+d_{v}(G)-2}\right)^{3}
$$

Equation (11) should be compared with Equation (10), noting that if instead of the exponent 3 we would set -0.5 , then we would arrive at the ordinary $A B C$ index. Preliminary studies ${ }^{11,134}$ indicate that $A Z I$ has an even better correlation potential than $A B C$, and the same will be confirmed also in the later sections of the present article. Until now, only a few properties of the augmented Zagreb index have been established. ${ }^{135,136}$

\section{Geometric-arithmetic Index}

Another recently conceived vertex-degree-based topological index utilizes the difference between the geometric and arithmetic means, and is defined as

$$
G A(G)=\sum_{u \sim v} \frac{\sqrt{d_{u}(G) d_{v}(G)}}{\frac{1}{2}\left[d_{u}(G)+d_{v}(G)\right]}
$$

where, of course, $\sqrt{d_{u} d_{v}}$ and $\frac{1}{2}\left(d_{u}+d_{v}\right)$ are the geometric and arithmetic means, respectively, of the degrees of the end-vertices of an edge. Recall that the former is always less than or equal to the later. The index was invented by Vukičević and Furtula ${ }^{137}$ and was named "geometric-arithmetic index".

Soon after the $G A$ index was defined via Equation (12), other "geometric-arithmetic" indices were introduced. The idea was to replace in Equation (12) the vertex degrees by some other vertex property. By this the second, third, ..., sixth "geometric-arithmetic" indices were constructed, whose chemical relevance is highly doubtful; for details see Reference 138, the reviews in References 139, 140, and the references quoted therein. Anyway, the index defined by Equation (12) is nowadays referred to as the "first geometricarithmetic index".

In addition to some mathematical studies of the $G A$ index, ${ }^{141-144}$ worth of chemists' interest are its applications to acyclic, unicyclic and bicyclic molecular graphs, ${ }^{145}$ as well as benzenoid hydrocarbons and phenylenes. ${ }^{146,147}$ The paper ${ }^{148}$ reports a comparison of the geometric-arithmetic and atom-bond connectivity indices.

\section{Harmonic Index}

In the 1980s, Siemion Fajtlowicz created a computer program for automatic generation of conjectures in graph theory. Then he examined the possible relations between countless graph invariants, among which there was a vertex-degree-based quantity ${ }^{149}$

$$
H(G)=\sum_{u \sim v} \frac{2}{d_{u}(G)+d_{v}(G)}
$$

With a single exception ${ }^{150} H(G)$ did not attract anybody's attention, especially not of chemists. Only in 2012, Zhang ${ }^{151,152}$ re-introduced this quantity, and called it "harmonic index". His works were followed by the recent paper. ${ }^{153}$ No chemical applications of the harmonic index were reported so far, but, knowing the present situation in mathematical chemistry, such researches are very much to be expected.

\section{Sum-connectivity Index}

The so-called "sum-connectivity index" is a recent invention by Bo Zhou and Nenad Trinajstić. ${ }^{154}$ They noticed that in the definition of Randić's branching index, ${ }^{16}$ Equation (1), there is no a priori reason for using the product $d_{u} \times d_{v}$ of vertex degrees, and this term may be replaced by the sum $d_{u}+d_{v}$. If so, then instead of Equation (1), one gets

$$
S C I(G)=\sum_{u \sim v} \frac{1}{\sqrt{d_{u}(G)+d_{v}(G)}}
$$

In view of Equation (14), the original Randic index R is sometimes referred to as the "product-connectivity index".

A number of properties of the sum-connectivity index have been determined, ${ }^{125,154-159}$ which again are bounds and characterization of graphs of various types, extremal with respect to $S C I$; details are found in the review. ${ }^{160}$ By comparing the product- and sumconnectivity indices, ${ }^{10,11,161,162}$ it was found that these have remarkably similar correlation properties.

\section{GENERAL MATHEMATICAL FORMULATION}

By comparing Equations (1,4,5,10-14) one may observe that all these topological indices are of the form

$$
T I=T I(G)=\sum_{u \sim v} F\left(d_{u}, d_{v}\right)
$$


where the summation goes over all pairs of adjacent vertices $u, v$ of the molecular graph $G$, and where $F=$ $F(x, y)$ is an appropriately chosen function. In particular,

$F(x, y)=\frac{1}{\sqrt{x y}}$

for the Randić (or connectivity) index

$F(x, y)=x+y$

for the first Zagreb index

$F(x, y)=x y$

for the second Zagreb index

$F(x, y)=\sqrt{\frac{x+y-2}{x y}}$

for the atom - bond connectivity $(\mathrm{ABC})$ index

$F(x, y)=\left(\frac{x y}{x+y-2}\right)^{3}$

for the augmented Zagreb index

$F(x, y)=\frac{2 \sqrt{x y}}{(x+y)}$

for the geometric - arithmetic index

$F(x, y)=\frac{2}{x+y}$

for the harmonic index

$F(x, y)=\frac{1}{\sqrt{x+y}}$

for the sum - connectivity index.

Also the logarithms of the three multiplicative Zagreb indices can be presented in the form of Equation (15), namely by choosing

$F(x, y)=2\left(\frac{\ln x}{x}+\frac{\ln y}{y}\right)$

for the logarithm of first multiplicative Zagreb index

$F(x, y)=\ln (x+y)$

for the logarithm of the modified first multiplicative Zagreb index

$F(x, y)=\ln x+\ln y$

for the logarithm of second multiplicative Zagreb index.
The evident question at this point is if there are other functions $F(x, y)$ that, by means of Equation (15), could be used to generate further vertex-degree-based topological indices. This idea was pursued by Damir Vukičević, who elaborated an entire theory, ${ }^{163-166}$ called "bond additive modeling", and designed a potentially infinite class of so-called "Adriatic indices". In addition to the above listed functions $F(x, y)$, Vukičević considered also Adriatic indices based on

$$
\begin{aligned}
& F(x, y)=\frac{x}{y}+\frac{y}{x}, F(x, y)=\frac{1}{|x-y|}, \\
& F(x, y)=|\sqrt{\log x}-\sqrt{\log y}|, F(x, y)=\left|\log ^{1 / 4} x-\log ^{1 / 4} y\right|
\end{aligned}
$$

and many others. The chemical applicability of some selected Adriatic indices was examined. ${ }^{167}$ Details can be found in the reviews. ${ }^{168,169}$

\section{GENERALIZATIONS AND PARAMETRIZATIONS}

The vertex-degree-based topological indices considered in the previous section were not only much studied by both chemists and mathematicians, but were subject of a variety of modifications and generalizations. In this section, we mainly focus our attention to the structuredescriptors that have emerged from the Randić index $R$, Equation (1), and only briefly mention the other analogous directions of research.

A detailed consideration of the definition of the Randić index, Equation (1), leads to two observations/questions.

First, Equation (1) can be rewritten as

$$
R=R(G)=\sum_{u \sim v}\left[d_{u}(G) d_{v}(G)\right]^{\lambda} \quad \text { for } \lambda=-\frac{1}{2}
$$

One may ask if this particular choice of the exponent $\lambda$ is necessary, and what would happen if some other value for $\lambda$ would be chosen. We return to this point in a while.

Second, Equations $(1,15)$ in general, consist of contributions (increments) coming from particular edges of the molecular graph $G$, i.e. contributions associated with the respective carbon-carbon bonds of the underlying molecule. For obvious chemical reasons, it is desirable to include into consideration also more complex structural details. This leads to a generalization of the Randić-index-concept that was put forward soon after the ordinary Randić index was invented. ${ }^{18}$

Let $G$ be a molecular graph, and let $u, v$, and $w$ be its three vertices forming a path of length two. In other words, $u \sim v$ and $v \sim w$. Then the "second-order connectivity index" is defined as 


$$
{ }^{2} R(G)=\sum_{u v w} \frac{1}{\sqrt{d_{u}(G) d_{v}(G) d_{w}(G)}}
$$

with summation going over all paths of length two, contained in the graph $G$. In full analogy, the third-order, fourth-order, etc. connectivity indices are defined as

$$
\begin{aligned}
& { }^{3} R(G)=\sum_{u v w x} \frac{1}{\sqrt{d_{u}(G) d_{v}(G) d_{w}(G) d_{x}(G)}} \\
& { }^{4} R(G)=\sum_{u \text { wwxy }} \frac{1}{\sqrt{d_{u}(G) d_{v}(G) d_{w}(G) d_{x}(G) d_{y}(G)}}
\end{aligned}
$$

etc., with summation embracing all paths $u v w x$ of length three, all paths $u v w x y$ of length four, etc. It is consistent to define the "zeroth-order connectivity index" as

$$
{ }^{0} R(G)=\sum_{v} \frac{1}{\sqrt{d_{v}(G)}}
$$

The higher-order connectivity indices have found numerous chemical applications..$^{18,19,170-179}$ In contrast to this, not many mathematical results have been obtained. ${ }^{20,180-183}$

If the exponent $\lambda$ in Equation (13) is chosen to be different than -0.5 , then we arrive at an infinite class of topological indices of the form

$$
R_{\lambda}(G)=\sum_{u \sim v}\left[d_{u}(G) d_{v}(G)\right]^{\lambda}
$$

that in the literature are usually called "general Randić indices" (although "generalized Randić index" would be more appropriate). The chemically most straightforward idea is to choose the parameter $\lambda$ so that the index $R_{\lambda}$ be optimally correlated with a particular physico-chemical property. ${ }^{184-186}$ Unfortunately, it happens that different physico-chemical properties require significantly different "optimal" $\lambda$-values. Vukičević considered the interesting problem, ${ }^{187,188}$ closely related to Randić's original work, ${ }^{16}$ namely which value of $\lambda$ provides the best measure of molecular branching.

The mathematical studies of the general Randic index and its higher-order variants is legion. The interested reader is referred to the books, ${ }^{20,21}$ review, ${ }^{189}$ and recent papers. ${ }^{190-192}$

In analogy to the generalized-Randić-index concept, Equation (17), the "variable first and second $\mathrm{Za}$ greb indices" were defined as ${ }^{193}$

$$
{ }^{\lambda} M_{1}(G)=\sum_{v} d_{v}(G)^{2 \lambda} \text { and }{ }^{\lambda} M_{2}(G)=\sum_{u \sim v}\left[d_{u}(G) d_{v}(G)\right]^{\lambda}
$$

but were so far studied only in a few papers. ${ }^{194-197}$ Using the same idea, by inserting a variable exponent on the right-hand side of Equation (14):

$$
S C I_{\lambda}(G)=\sum_{u \sim v}\left[d_{u}(G)+d_{v}(G)\right]^{\lambda}
$$

the "general sum-connectivity index", was introduced by Zhou and Trinajstic ${ }^{198}$ and eventually elaborated by the same authors and others. ${ }^{199-202}$

When instead of the molecular graph $G$ its line graph $L(G)$ is used, then instead of the ordinary Randic index one arrives at Estrada's "edge connectivity index" ${ }^{" 203-205}$ A comparison between Randić and edgeconnectivity indices of benzenoid hydrocarbons was reported. ${ }^{206}$

In the case of Zagreb indices, the transformation $G \rightarrow L(G)$ yields the "reformulated Zagreb indices". $207-209$

The last modifications to be mentioned here are the so-called "coindices". These are graph invariants of the form Equation (15), in which the summation goes not over pairs of adjacent, but over pairs of non-adjacent vertices. So far, only the "Zagreb coindices" attracted some attention, ${ }^{57,210-214}$ but their chemical significance and applicability is doubtful.

\section{A SIMPLE COMPARATIVE TESTING OF DEGREE-BASED TOPOLOGICAL INDICES}

We report here the results of a comparative test ${ }^{11}$ of how well some of the above-specified topological indices are correlated with two simple physico-chemical parameters of octane isomers. These parameters were chosen to be the standard heats of formation (representative for thermochemical properties) and the normal boiling points (representative for intermolecular, van-der-Waals-type, interactions). In order to avoid size-dependency problems, we considered a class of isomers. In order to minimize problems caused by steric effects, polar functional groups, hydrogen bonding, and similar, the test was done on a class of alkanes. Octanes are particularly convenient for such studies, because the number of their structural isomers (18) is large enough to make statistical inferences reliable, and because experimental data are available for all isomers.

From the formulas displayed in the preceding sections, it is evident that for $\lambda=-0.5$, the general Randic index and the general sum-connectivity index are equal to the ordinary Randić index and the ordinary sumconnectivity index, respectively. For $\lambda=1$, the general Randić index and the general sum-connectivity index coincide with the second and first Zagreb indices, respectively. In addition, for the $\lambda=-1$, general sumconnectivity index reduces to the harmonic index. In view of this, we have tested the general Randić index 
for $\lambda=-3,-2,-1,2,3$, and the general sum-connectivity index for $\lambda=-3,-2,2,3$. A total of 20 different vertexdegree-based topological indices of the form in Equation (15) were tested.

Experimental data for the heats of formations and boiling points of all octane isomers were taken from standard reference databases. ${ }^{215}$

In each particular case, the possibility of curvilinear correlation was tested. In not a single case, the existence of such correlation could be established. Therefore, the quality of the examined correlations can be assessed and compared by their correlation coefficients. These are collected in Table 1.

From Table 1 we see that for each topological index, the two correlation coefficients are nearly equal, thus implying almost identical conclusions concerning the quality of this index. This detail confirms that our choice of the two test parameters (whose physicochemical nature is quite different), was a reasonable one, and that the results of our comparison are representative for the general quality of the topological indices considered.

By inspection of the data given in Table 1, it is possible to draw a number of conclusions, some quite unfavorable for several well-established topological indices.

First of all, the famous and much studied Zagreb indices $\left(M_{1}\right.$ and $\left.M_{2}\right)$ are found to be completely inadequate for any structure-property correlation. This important detail seems to have been ignored in the recent comprehensive surveys. ${ }^{49,52}$

In addition, results for $\ln \Pi_{1}, \ln \Pi_{1}^{*}$, and $\ln \Pi_{2}$, reveal that the recently advocated idea of multiplicative Zagreb indices ${ }^{90-93}$ did not pass the test. Consequently, it may be justified to halt any further elaboration of the theory of these multiplicative indices.

The Randić index $(R)$ is one of the most often applied molecular-graph-based structure descriptors. It is therefore remarkable to realize that its modification $R_{\lambda}$ with exponent $\lambda=-1$ (and to a lesser extent also with exponent $\lambda=-2$ ) performs significantly better than the ordinary variant (with exponent $\lambda=-0.5$ ). This fact was mentioned neither in the recent reviews ${ }^{22,23}$ by Randić himself, nor in the books. ${ }^{18-20}$

From a practical point of view, topological indices for which the absolute value of the correlation coefficients is less than 0.8 , can be characterized as useless. This especially applies to the variable Randić index $R_{\lambda}$ and the variable sum-connectivity index $S C I_{\lambda}$ with exponents $\lambda>1$.

The newly proposed sum-connectivity index ${ }^{154}$ and harmonic index, ${ }^{151,152}$ although having reasonably good correlation abilities, are outperformed by several older indices. Therefore, the justification of their use in structure-property correlations is questionable.
Table 1. Correlation coefficients $r\left(\Delta H_{f}^{o}\right)$ and $r(b . p$.$) for the$ correlation between some vertex-degree-based topological indices and the standard heats of formation $\Delta H_{f}^{o}$ and normal boiling points (b.p.) of isomeric octanes

\begin{tabular}{lrr}
\hline Index & $r\left(\Delta H_{f}^{o}\right)$ & $r(b . p)$. \\
\hline$R$, Equation (1) & -0.846 & 0.816 \\
$R_{\lambda}$, Equation (17), $\lambda=-3$ & -0.827 & 0.791 \\
$R_{\lambda}$, Equation (17), $\lambda=-2$ & -0.869 & 0.832 \\
$R_{\lambda}$, Equation (17), $\lambda=-1$ & -0.886 & 0.853 \\
$R_{\lambda}$, Equation (17), $\lambda=2$ & 0.447 & -0.372 \\
$R_{\lambda}$, Equation (17), $\lambda=3$ & 0.437 & -0.335 \\
$M_{1}$, Equation (3) & 0.757 & -0.713 \\
$M_{2}$, Equation (4) & 0.536 & -0.491 \\
$A B C$, Equation (10) & 0.890 & -0.860 \\
$A Z I$, Equation (11) & -0.921 & 0.922 \\
$G A$, Equation (12) & -0.854 & 0.818 \\
$H$, Equation (13) & -0.844 & 0.817 \\
$S C I$, Equation (14) & -0.827 & 0.797 \\
$S C I \lambda$, Equation (18), $\lambda=-3$ & -0.870 & 0.851 \\
$S C I_{\lambda}$, Equation (18), $\lambda=-2$ & -0.865 & 0.844 \\
$S C I_{\lambda}$, Equation (18), $\lambda=2$ & 0.705 & -0.649 \\
$S C I_{\lambda}$, Equation (18), $\lambda=3$ & 0.655 & -0.587 \\
$\ln \Pi_{1}$, Equation (7) & -0.745 & 0.728 \\
$\ln \Pi_{2}$, Equation (8) & 0.752 & -0.723 \\
$\ln \Pi_{1}^{*}$, Equation (9) & 0.806 & -0.772 \\
\hline
\end{tabular}

The only vertex-degree-based topological index that has correlation coefficients over 0.9 is the augmented Zagreb index, recently invented by Furtula et al. ${ }^{134}$ We may say that only this index has successfully passed our test. Consequently, this index should be preferred in designing quantitative structure-property relations.

The second-best vertex-degree-based molecular structure-descriptor appears to be Estrada's atom-bond connectivity index $(A B C)$.

\section{ADVANCED COMPARATIVE TESTING OF DEGREE-BASED TOPOLOGICAL INDICES}

In order to reduce the arbitrariness in the production of novel topological indices, several criteria were put forward that such a molecular structure descriptor should be required to satisfy. The first set of such criteria was given by Randić. ${ }^{216}$ Similar lists were proposed also elsewhere. ${ }^{217-219}$ One of these criteria is always that a topological index "should change gradually with gradual change in (molecular) structure". This property may be called the smoothness of the topological index in question. In order to quantify this concept, two measures thereof have been introduced, ${ }^{10}$ called "struc- 
ture sensitivity" $(S S)$ and "abruptness" $(A b r)$. These are defined as follows. ${ }^{10}$

Let $G$ be a molecular graph and $T I$ the topological index considered. The set $\Gamma(G)$ consists of all connected graphs obtained from $G$, by replacing one of its edges by another edge. (Intuitively, the elements of $\Gamma(G)$ are those graphs that are structurally most similar to $G$.) Then

$$
\begin{gathered}
S S(T I, G)=\frac{1}{|\Gamma(G)|} \sum_{\gamma \in \Gamma(G)}\left|\frac{T I(G)-T I(\gamma)}{T I(G)}\right| \\
\operatorname{Abr}(T I, G)=\max _{\gamma \in \Gamma(G)}\left|\frac{T I(G)-T I(\gamma)}{T I(G)}\right|
\end{gathered}
$$

According to Equation (19), SS is the average relative sensitivity of $T I$ to small changes in the structure of the graph $G$. According to Equation (20), Abr shows how much a small structural change may cause a jumpwise (large) change in the considered topological index. From a practical point of view, the best is if the structure sensitivity is as large as possible, but the abruptness is as small as possible.

The smoothness of some of the above considered vertex-degree-based topological indices was recently examined. ${ }^{10}$ This was done for the set of all trees with $n=6,7, \ldots, 13$ vertices. The results for $n=8$ are shown in Table 2. Computational details and the other calculated values for $S S$ and $A b r$ can be found in the paper. ${ }^{10}$ Here we state only some of the conclusions obtained.

The degree-based topological indices with the greatest structure sensitivity were found to be the augmented Zagreb index $A Z I$ and the second Zagreb index $M_{2}$. For instance, for trees with 10 vertices, $S S(A Z I)=$ $0.118, S S\left(M_{2}\right)=0.103$, followed by $S S\left(M_{1}\right)=0.073$, etc, whereas for trees with 12 vertices, $S S\left(M_{2}\right)=0.089$, $S S(A Z I)=0.086$, followed by $S S\left(M_{1}\right)=0.058$, etc. The same ordering holds for other examined values of $n$. Thus, at least in the case of trees, the degree-based topological indices with best structure sensitivity are the augmented and the second Zagreb indices, and these appear to be superior to the other indices studied.

As a sort of unpleasant surprise, the very same indices were found to have the greatest abruptness. Thus, for $n=12$, the second Zagreb index and the augmented Zagreb index have maximum abruptness $\left(\operatorname{Abr}\left(M_{2}\right)=\right.$ 0.270 and $\operatorname{Abr}(A Z I)=0.0217$, followed by $\operatorname{Abr}\left(M_{1}\right)=$ $0.149)$. The atom-bond connectivity index has the least structure sensitivity, which disagrees with the claims ${ }^{104-106}$ that $A B C$ is a very good measure of branchingdependent thermodynamic properties of alkanes.

It is also interesting to note that the classical Randić index $R$ and the recently proposed sumconnectivity and geometric-arithmetic indices (SCI and $G A$ ), have almost identical structure sensitivities. For
Table 2. Arithmetic means of the structure sensitivity $(S S)$ and abruptness $(\mathrm{Abr})$ of selected vertex-degree-based topological indices for trees with 8 vertices

\begin{tabular}{lcc}
\hline Index & $S S$ & $A b r$ \\
\hline$R$ & 0.0484 & 0.0855 \\
$M_{1}$ & 0.0964 & 0.1815 \\
$M_{2}$ & 0.1209 & 0.2546 \\
$A B C$ & 0.0382 & 0.0704 \\
$A Z I$ & 0.2017 & 0.3384 \\
$G A$ & 0.0474 & 0.0823 \\
$H$ & 0.0972 & 0.1691 \\
$S C I$ & 0.0482 & 0.0850 \\
$\ln \Pi_{1}$ & 0.0988 & 0.1819 \\
$\ln \Pi_{2}$ & 0.0665 & 0.1264 \\
$\ln \Pi_{1}^{*}$ & 0.0610 & 0.1122 \\
\hline
\end{tabular}

instance, for $n=12$, we calculated $S S(R)=0.026$, $S S(S C I)=0.026$, and $S S(G A)=0.024$; for $n=8$, see Table 2. This finding sheds doubts (at least in the case of trees) as to whether the introduction of the sumconnectivity and geometric-arithmetic indices was fully justified.

\section{REFERENCES}

1. H. Van de Waterbeemd, R. E. Carter, G. Grassy, H. Kubiny, Y. C. Martin, M. S. Tutte, and P. Willet, Pure Appl. Chem. 69 (1997) 1137.

2. J. Devillers and A. T. Balaban (Eds.), Topological Indices and Related Descriptors in: QSAR and QSPR, Gordon \& Breach, Amsterdam,1999.

3. R. Todeschini and V. Consonni, Handbook of Molecular Descriptors, Wiley-VCH, Weinheim, 2000.

4. R. Todeschini and V. Consonni, Molecular Descriptors for Chemoinformatics, Vols. 1 \& 2, Wiley-VCH, Weinheim, 2009.

5. I. Gutman and B. Furtula (Eds.), Novel Molecular Structure Descriptors - Theory and Applications, Vols. 1 \& 2, Univ. Kragujevac, Kragujevac, 2010.

6. I. Gutman and B. Furtula (Eds.), Distance in Molecular Graphs Theory, Univ. Kragujevac, Kragujevac, 2012.

7. I. Gutman and B. Furtula (Eds.), Distance in Molecular Graphs Applications, Univ. Kragujevac, Kragujevac, 2012.

8. I. Gutman, Iran. J. Math. Chem. 3 (2012) 95.

9. I. Gutman and B. Furtula, J. Serb. Chem. Soc. 77 (2012) 1031.

10. B. Furtula, I. Gutman, and M. Dehmer, Appl. Math. Comput. 219 (2013) 8973.

11. I. Gutman and J. Tošović, J. Serb. Chem. Soc. 78 (2013) 805.

12. N. Trinajstić, Chemical Graph Theory, CRC Press, Boca Raton, 1983.

13. I. Gutman and O. E. Polansky, Mathematical Concepts in Organic Chemistry, Springer, Berlin, 1986.

14. I. Gutman and N. Trinajstić, Chem. Phys. Lett. 17 (1972) 535.

15. I. Gutman, B. Ruščić, N. Trinajstić, and C. F. Wilcox, J. Chem. Phys. 62 (1975) 3399.

16. M. Randić, J. Am. Chem. Soc. 97 (1975) 6609.

17. L. B. Kier, L. H. Hall, W. J. Murray, and M. Randić, J. Pharm. Sci. 64 (1975) 1971. 
18. L. B. Kier and L. H. Hall, Molecular Connectivity in Chemistry and Drug Research, Academic Press, New York, 1976.

19. L. B. Kier and L. H. Hall, Molecular Connectivity in StructureActivity Analysis, Wiley, New York, 1986.

20. X. Li and I. Gutman, Mathematical Aspects of Randić-Type Molecular Structure Descriptors, Univ. Kragujevac, Kragujevac, 2006.

21. I. Gutman and B. Furtula (Eds.), Recent Results in the Theory of Randić Index, Univ. Kragujevac, Kragujevac, 2008.

22. M. Randić, MATCH Commun. Math. Comput. Chem. 59 (2008) 5.

23. M. Randić, J. Mol. Graphics Modell. 20 (2001) 19.

24. L. Pogliani, Chem. Rev. 100 (2000) 3827.

25. X. Li and Y. Shi, MATCH Commun. Math. Comput. Chem. 59 (2008) 127

26. X. Li, Y. Shi, and L. Wang, in: Recent Results in the Theory of Randic Index, I. Gutman and B. Furtula (Eds.), Univ. Kragujevac, Kragujevac, 2008, pp. 9-47.

27. L. B. Kier and L. H. Hall, Eur. J. Med. Chem. 12b (1977) 307.

28. L. B. Kier and L. H. Hall, Croat. Chem. Acta 75 (2002) 371.

29. E. Estrada, Internet Electron. J. Mol. Design 1 (2002) 360.

30. E. Estrada, J. Phys. Chem. A 106 (2002) 9085.

31. B. Bollobás and P. Erdős, Ars Combin. 50 (1998) 225.

32. B. Bollobás, P. Erdős, and A. Sarkar, Discr. Math. 200 (1999) 5.

33. X. Li, Y. Shi, and L. Wang, MATCH Commun. Math. Comput. Chem. 68 (2012) 843.

34. L. Zuo, Bull. Malays. Math. Sci. Soc. 35 (2012) 411.

35. M. Liang and B. Liu, Discr. Math. 312 (2012) 2446.

36. M. Liang and B. Liu, Discr. Appl. Math. 161 (2013) 212-216.

37. I. Gutman, O. Araujo, and J. Rada, ACH Models Chem. 137 (2000) 653.

38. G. Caporossi, I. Gutman, P. Hansen, and L. Pavlović, Comput. Biol. Chem. 27 (2003) 85.

39. M. Cavers, S. Fallat, and S. Kirkland, Lin. Algebra Appl. 433 (2010) 172.

40. Ş. B. Bozkurt, A. D. Güngör, I. Gutman, and A. S. Çevik, MATCH Commun. Math. Comput. Chem. 64 (2010) 239.

41. I. Gutman, B. Furtula, and Ş. B. Bozkurt, Lin. Algebra Appl., in press.

42. A. T. Balaban, I. Motoc, D. Bonchev, and O. Mekenyan, Topics Curr. Chem. 114 (1983) 21.

43. F. K. Bell, Lin. Algebra Appl. 161 (1992) 45.

44. D. de Caen, Discr. Math. 185 (1998) 245.

45. U. N. Peled, R. Petreschi, and A. Sterbini, J. Graph Theory 31 (1999) 283.

46. K. C. Das, Kragujevac J. Math. 25 (2003) 31.

47. K. C. Das, Discr. Math. 285 (2004) 57.

48. S. M. Cioabă, Discr. Math. 306 (2006) 1959.

49. S. Nikolić, G. Kovačević, A. Miličević, and N. Trinajstić, Croat. Chem. Acta 76 (2003) 113.

50. I. Gutman and K. C. Das, MATCH Commun. Math. Comput. Chem. 50 (2004) 83.

51. K. C. Das and I. Gutman, MATCH Commun. Math. Comput. Chem. 52 (2004) 103.

52. N. Trinajstić, S. Nikolić, A. Miličević, and I. Gutman, Kem. Ind. 59 (2010) 577 (in Croatian).

53. D. Vukičević and A. Graovac, Croat. Chem. Acta 77 (2004) 501.

54. D. Vukičević, N. Trinajstić, MATCH Commun. Math. Comput. Chem. 53 (2005) 111.

55. T. Došlić, Iran. J. Math. Chem. 3 (2012) 25.

56. S. Nikolić, I. M. Tolić, N. Trinajstić, and I. Baučić, Croat. Chem. Acta 73 (2000) 909.

57. T. Došlić, B. Furtula, A. Graovac, I. Gutman, S. Moradi, and Z. Yarahmadi, MATCH Commun. Math. Comput. Chem. 66 (2011) 613.

58. T. Došlić, T. Réti, D. Vukičević, Chem. Phys. Lett. 512 (2011) 283.

59. H. Deng, MATCH Commun. Math. Comput. Chem. 57 (2007) 597.
60. T. Rèti, I. Gutman, and D. Vuki čević. Math. Nanosci. 1 (2011) 1.

61. M. Liu and B. Liu, MATCH Commun. Math. Comput. Chem. 67 (2012) 439.

62. M. Milošević, T. Réti, and D. Stevanović, MATCH Commun. Math. Comput. Chem. 68 (2012) 157.

63. T. Réti, MATCH Commun. Math. Comput. Chem. 68 (2012) 169.

64. M. Arezoomand and B. Taeri, MATCH Commun. Math. Comput. Chem. 69 (2013) 131.

65. K. C. Das, K. Xu, and I. Gutman, MATCH Commun. Math. Comput. Chem. 70 (2013) 301.

66. P. S. Ranjini, V. Lokesha, and I. N. Cangül, Appl. Math. Comput. 218 (2011) 699.

67. H. Abdo, D. Dimitrov, and I. Gutman, Discr. Appl. Math. 160 (2012) 1.

68. S. Li, H. Yang, and Q. Zhao, Filomat 26 (2012) 1189.

69. Z. Yarahmadi, A. R. Ashrafi, and S. Moradi, Appl. Math. Lett. 25 (2012) 166.

70. R. Lang, X. Deng, and H. Lu, Bull. Malays. Math. Sci. Soc. 36 (2013) 1.

71. P. Hansen and D. Vukičević, Croat. Chem. Acta 80 (2007) 165.

72. D. Vukičević and A, Graovac, MATCH Commun. Math. Comput. Chem. 57 (2007) 587.

73. A. Ilić and D. Stevanović, MATCH Commun. Math. Comput. Chem. 62 (2009) 681.

74. L. Sun and S. Wei, MATCH Commun. Math. Comput. Chem. 62 (2009) 699.

75. K. C. Das, MATCH Commun. Math. Comput. Chem. 63 (2010) 433.

76. G. Caporossi, P. Hansen, and D. Vukičević, MATCH Commun. Math. Comput. Chem. 63 (2010) 441.

77. M. Zhang and B. Liu, MATCH Commun. Math. Comput. Chem. 63 (2010) 461

78. S. Stevanović, Croat. Chem. Acta 84 (2011) 17.

79. V. Andova, S. Bogoev, D. Dimitrov, M. Pilipczuk, and R. Škrekovski, Discr. Appl. Math. 159 (2011) 852.

80. V. Andova, N. Cohen, and R. Škrekovski, MATCH Commun. Math. Comput. Chem. 65 (2011) 647.

81. V. Andova and M. Petruševski, MATCH Commun. Math. Comput. Chem. 65 (2011) 685.

82. D. Vukičević, I. Gutman, B. Furtula, V. Andova, and D. Dimitrov, MATCH Commun. Math. Comput. Chem. 66 (2011) 627.

83. S. Bogoev, MATCH Commun. Math. Comput. Chem. 66 (2011) 647.

84. V. Andova, N. Cohen, and R. Škrekovski, Ars Math. Contemp. 5 (2012) 73.

85. Stevanović, M. Milanič, MATCH Commun. Math. Comput. Chem. 68 (2012) 147.

86. B. Liu and Z. You, in: Novel Molecular Structure Descriptors Theory and Applications I, I. Gutman and B. Furtula (Eds.), Univ. Kragujevac, Kragujevac, 2010, pp. 117-239.

87. B. Liu and Z. You, MATCH Commun. Math. Comput. Chem. 65 (2011) 581 .

88. H. Narumi and M. Katayama, Mem. Fac. Engin. Hokkaido Univ. 16 (1984) 209.

89. Ž. Tomović and I. Gutman, J. Serb. Chem. Soc. 66 (2001) 243.

90. I. Gutman and M. Ghorbani, Appl. Math. Lett. 25 (2012) 1435.

91. D. J. Klein and V. R. Rosenfeld, in: Novel Molecular Structure Descriptors - Theory and Applications II, I. Gutman and B. Furtula (Eds.), Univ. Kragujevac, Kragujevac, 2010, pp. 79-90.

92. D. J. Klein and V. R. Rosenfeld, MATCH Commun. Math. Comput. Chem. 64 (2010) 607.

93. R. Todeschini and V. Consonni, MATCH Commun. Math. Comput. Chem.64 (2010) 359.

94. M. Eliasi, A. Iranmanesh, and I. Gutman, MATCH Commun. Math. Comput. Chem. 68 (2012) 217.

95. I. Gutman, Bull. Int. Math. Virt. Inst. 1 (2011) 13.

96. T. Réti, I. Gutman, Bull. Int. Math. Virt. Inst. 2 (2012) 133. 
97. A. Iranmanesh, M. A. Hosseinzadeh, and I. Gutman, Iran. J. Math. Chem. 3(2) (2012) 145.

98. J. Liu and Q. Zhang, MATCH Commun. Math. Comput. Chem. 68 (2012) 231.

99. K. Xu and H. Hua, MATCH Commun. Math. Comput. Chem. 68 (2012) 241.

100. K. Xu and K. C. Das, MATCH Commun. Math. Comput. Chem. $\mathbf{6 8}(2012) 257$

101. M. Ghorbani and N. Azimi, Iran. J. Math. Chem. 3 (2012) 137.

102. M. Eliasi, Trans. Comb. 1 (4) (2012) 17.

103. M. Eliasi and D. Vukičević, MATCH Commun. Math. Comput. Chem. 69 (2013) 765.

104. E. Estrada, L. Torres, L. Rodríguez, and I. Gutman, Indian J. Chem. 37A (1998) 849.

105. E. Estrada, Chem. Phys. Lett. 463 (2008) 422.

106. I. Gutman, J. Tošović, S. Radenković, and S. Marković, Indian J. Chem. 51A (2012) 690.

107. J. Chen and X. Guo, MATCH Commun. Math. Comput. Chem. 65 (2011) 713.

108. K. C. Das, I. Gutman, and B. Furtula, Chem. Phys. Lett. 511 (2011) 452.

109. B. Furtula, A. Graovac, and D. Vukičević, Discr. Appl. Math. 157 (2009) 2828.

110. I. Gutman and B. Furtula, MATCH Commun. Math. Comput. Chem. 68 (2012) 131.

111. I. Gutman, B. Furtula, and M. Ivanović, MATCH Commun. Math. Comput. Chem. 67 (2012) 467.

112. B. Furtula, I. Gutman, M. Ivanović, and D. Vukičević, Appl. Math. Comput. 219 (2012) 767.

113. W. Lin, X. Lin, T. Gao, and X. Wu, MATCH Commun. Math. Comput. Chem. 69 (2013) 549.

114. M. B. Ahmadi, S. A. Hosseini, and P. Salehi Nowbandegani, MATCH Commun. Math. Comput. Chem. 69 (2013) 559.

115. M. B. Ahmadi, S. A. Hosseini, and M. Zarrinderakht, MATCH Commun. Math. Comput. Chem. 69 (2013) 565.

116. I. Gutman, B. Furtula, M. B. Ahmadi, S. A. Hosseini, P. Salehi Nowbandegani, and M. Zarrinderakht, Filomat 27 (2013) 1075.

117. D. Dimitrov, Appl. Math. Comput. 220 (2013), in pres.

118. S. A. Hosseini, M. B. Ahmadi, and I. Gutman, MATCH Commun. Math. Comput. Chem. 71 (2014) 5.

119. K. C. Das, Discr. Appl. Math. 158 (2010) 1181.

120. R. Xing, B. Zhou, and Z. Du, Discr. Appl. Math. 158 (2010) 1536.

121. G. A. Fath-Tabar, B. Vaez-Zadah, A. R. Ashrafi, and A. Graovac, Discr. Appl. Math. 159 (2011) 1323.

122. R. Xing, B. Zhou, and F. Dong, Discr. Appl. Math. 159 (2011) 1617.

123. B. Zhou and R. Xing, Z. Naturforsch. 66a (2011) 61.

124. J. S. Chen and J. P. Liu, J. Guangxi Teachers Educ. Univ. 28 (2) (2011) 8 (in Chinese).

125. B. Horoldagva and I. Gutman, MATCH Commun. Math. Comput. Chem. 65 (2011) 723.

126. L. Gan, H. Hou, and B. Liu, MATCH Commun. Math. Comput. Chem. 66 (2011) 669.

127. L. Gan. B. Liu, and Z. You, MATCH Commun. Math. Comput. Chem. 68 (2012) 137.

128. X. Ke, Polyc. Arom. Comp. 32 (2012) 27.

129. R. Xing and B. Zhou, Filomat 26 (2012) 683.

130. K. C. Das, I. Gutman, and B. Furtula, Filomat 26 (2012) 733.

131. T. S. Vassilev and L. J. Huntington, Appl. Math. 2 (1) (2012) 8.

132. J. Chen, J. Liu, and X. Guo, Appl. Math. Lett. 25 (2012) 1077.

133. W. Lin, T. Gao, Q. Chen, and X. Lin, MATCH Commun. Math. Comput. Chem. 69 (2013) 571.

134. B. Furtula, A. Graovac, D. Vukičević, J. Math. Chem. 48 (2010) 370 .

135. D. Wang, Y. Huang, and B. Liu, MATCH Commun. Math. Comput. Chem. 68 (2012) 209.
136. Y. Huang, B. Liu, and L. Gan, MATCH Commun. Math. Comput. Chem. 67 (2012) 483.

137. D. Vukičević and B. Furtula, J. Math. Chem. 46 (2009) 1369.

138. G. H. Fath-Tabar, B. Furtula, and I. Gutman, J. Math. Chem. 47 (2010) 477.

139. B. Furtula and I. Gutman, in: Novel Molecular Structure Descriptors - Theory and Applications II, I. Gutman and B. Furtula (Eds.), Univ. Kragujevac, Kragujevac, 2010, pp. 137-172.

140. K. C. Das, I. Gutman, and B. Furtula, MATCH Commun. Math. Comput. Chem. 65 (2011) 595.

141. Y. Yuan, B. Zhou, and N. Trinajstić, J. Math. Chem. 47 (2010) 833.

142. K. C. Das, On geometric-arithmetic index of graphs, $M A T C H$ Commun. Math. Comput. Chem. 64 (2010) 619.

143. K. C. Das, I. Gutman, and B. Furtula, Discr. Appl. Math. 159 (2011) 2030

144. M. Mogharrab and G. H. Fath-Tabar, MATCH Commun. Math. Comput. Chem. 65 (2011) 33.

145. Z. Du, B. Zhou, and N. Trinajstić, MATCH Commun. Math. Comput. Chem. 66 (2011) 681.

146. L. Xiao, S. Chen, Z. Guo, and Q. Chen, Int. J. Contemp. Math. Sci. 5 (2010) 2225.

147. Z. Yarahmadi, Iran. J. Math. Chem. 2 (2011) 101.

148. K. C. Das and N. Trinajstić, Chem. Phys. Lett. 497 (2010) 149.

149. S. Fajtlowicz, Congr. Numer. 60 (1987) 187.

150. O. Favaron, M. Mahéo, and J. F. Saclé, Discr. Math. 111 (1993) 197.

151. L. Zhong, Appl. Math. Lett. 25 (2012) 561.

152. L. Zhong, Ars Combin. 104 (2012) 261.

153. R. Wu, Z. Tang, and H. Deng, Filomat 27 (2013) 49.

154. B. Zhou and N. Trinajstić, J. Math. Chem. 46 (2009) 1252.

155. Z. Du, B. Zhou, and N. Trinajstić, J. Math. Chem. 47 (2010) 842.

156. R. Xing, B. Zhou, and N. Trinajstić, J. Math. Chem. 48 (2010) 583.

157. F. Ma and H. Deng, Math. Comput. Model. 54 (2011) 497.

158. S. Wang, B. Zhou, and N. Trinajstić, Filomat 25 (2011) 29.

159. Z. Du and B. Zhou, Bull. Malays. Math. Sci. Soc. 35 (2012) 101.

160. B. Lučić, S. Nikolić, N. Trinajstić, B. Zhou, and S. Ivaniš Turk, in: Novel Molecular Structure Descriptors - Theory and Applications I, I. Gutman and B. Furtula (Eds.), Univ. Kragujevac, Kragujevac, 2010, pp. 101-136.

161. B. Lučić, N. Trinajstić, and B. Zhou, Chem. Phys. Lett. 475 (2009) 146 .

162. D. Vukičević and N. Trinajstić, Croat. Chem. Acta 83 (2010) 349.

163. D. Vukičević and M. Gašperov, Croat. Chem. Acta 83 (2010) 243.

164. D. Vukičević, Croat. Chem. Acta 83 (2010) 261.

165. D. Vukičević, Croat. Chem. Acta 84 (2011) 93.

166. D. Vukičević and J. Đurđević, Chem. Phys. Lett. 515 (2011) 186.

167. D. Vukičević, Croat. Chem. Acta 84 (2011) 87.

168. D. Vukičević, in: Novel Molecular Structure Descriptors Theory and Applications II, I. Gutman and B. Furtula (Eds.), Univ. Kragujevac, Kragujevac, 2010, pp. 205-216.

169. D. Vukičević, , in: Novel Molecular Structure Descriptors Theory and Applications II, I. Gutman and B. Furtula (Eds.), Univ. Kragujevac, Kragujevac, 2010, pp. 269-302.

170. L. Pogliani, J. Phys. Chem. 99 (1995) 925.

171. L. Pogliani, Croat. Chem. Acta 69 (1996) 95.

172. L. Pogliani, J. Chem. Inf. Comput. Sci. 39 (1999) 104.

173. S. Nikolić, N. Trinajstić, S. Ivaniš, Croat. Chem. Acta 72 (1999) 875.

174. S. Nikolić and N. Raos, Croat. Chem. Acta 74 (2001) 621.

175. L. Pogliani, Croat. Chem. Acta 75 (2002) 409.

176. A. Miličević and N. Raos, Polyhedron 25 (2006) 2800.

177. J. Zhang, H. Deng, and S. Chen, J. Math. Chem. 42 (2007) 941.

178. N. Raos and A. Miličević, Arh. Hig. Rada Toksikol. 60 (2009) 
123.

179. H.Deng, MATCH Commun. Math. Comput. Chem. 64 (2010) 471.

180. J. Zhang, H. Deng, and S. Chen, J. Math. Chem. 42 (2007) 941.

181. I. G. Yero, J. A. Rodríguez-Velázquez, and I. Gutman, Chem. Phys. Lett. 489 (2010) 118.

182. S. Li and M. Zhang, Math. Comput. Model. 53 (2011) 1990.

183. L. Lin and M. Lu, Ars Combin. 104 (2012) 381.

184. L. Clark and I. Gutman, J. Math. Chem. 43 (2008) 32.

185. I. Gutman and M. Lepović, J. Serb. Chem. Soc. 66 (2001) 605.

186. I. Gutman, D. Vidović, and A. Nedić, J. Serb. Chem. Soc. 67 (2002) 87

187. D. Vukičević, MATCH Commun. Math. Comput. Chem. 64 (2010) 443.

188. D. Vukičević, Discr. Appl. Math. 158 (2010) 2056.

189. B. Liu and M. Liu, Distance, in: Molecular Graphs - Theory, I. Gutman and B. Furtula (Eds.), Univ. Kragujevac, Kragujevac, 2012, pp. 231-282.

190. R. Lang, MATCH Commun. Math. Comput. Chem. 64 (2010) 453.

191. R. Wu and H. Deng, MATCH Commun. Math. Comput. Chem. 64 (2010) 459.

192. M. Zhang and S. Li, J. Math. Chem. 49 (2011) 325.

193. A. Miličević, S. Nikolić, Croat. Chem. Acta 77 (2004) 97.

194. D. Vukičević, MATCH Commun. Math. Comput. Chem. 57 (2007) 633.

195. D. Vukičević and A. Graovac, MATCH Commun. Math. Comput. Chem. 60 (2008) 37.

196. Y. Huang. B. Liu, and M. Zhang, MATCH Commun. Math. Comput. Chem. 63 (2010) 453.

197. B. Liu, M. Zhang, and Y. Huang, MATCH Commun. Math. Comput. Chem. 65 (2011) 671.

198. B. Zhou and N. Trinajstić, J. Math. Chem. 47 (2010) 210.

199. Z. Du, B. Zhou, and N. Trinajstić, J. Math. Chem. 48 (2010) 697.

200. S. Chen, F. Xia, and J. Yang, Iran. J. Math. Chem. 1 (2) (2010) 97.

201. Z. Du, B. Zhou, and N. Trinajstić, Appl. Math. Lett. 24 (2011)
402.

202. I. Tomescu and S. Kanwal, MATCH Commun. Math. Comput. Chem. 69 (2013) 535.

203. E. Estrada, L. Rodríguez, J. Chem. Inf. Comput. Sci. 39 (1999) 1037.

204. E. Estrada, J. Chem. Inf. Comput. Sci. 39 (1999) 1042.

205. I. Gutman and E. Estrada, J. Chem. Inf. Comput. Sci. 36 (1996) 541 .

206. S. Nikolić, N. Trinajstić, I. Baučić, J. Chem. Inf. Comput. Sci. 38 (1998) 42

207. A. Miličević, S. Nikolić, and N. Trinajstić, Mol. Diversity 8 (2004) 393.

208. B. Zhou and N. Trinajstić, J. Math. Chem. 48 (2010) 714.

209. A. Ilić and B. Zhou, Discr. Appl. Math. 160 (2012) 204.

210. A. R. Ashrafi, T. Došlić, and A. Hamzeh, Discr. Appl. Math. 158 (2010) 1571.

211. A. R. Ashrafi, T. Došlić, and A. Hamzeh, MATCH Commun. Math. Comput. Chem. 65 (2011) 85.

212. K. C. Das I. Gutman, and B. Horoldagva, MATCH Commun. Math. Comput. Chem. 68 (2012) 189.

213. H. Hua and S. Zhang, MATCH Commun. Math. Comput. Chem. 68 (2012) 199

214. H. Hua, A. Ashrafi, and L. Zhang, Filomat 26 (2012) 1210.

215. NIST Standard Reference Database, http://webbook.gov/chemistry.

216. M. Randić, Croat. Chem. Acta 64 (1991) 43.

217. M. Krein, T. W. Huang, and L. Morkowchuk, Statistical Modelling of Molecular Descriptors, in: QSAR/QSPR, M. Dehmer, K. Varmuza, and D. Bonchev (Eds.), Wiley-Blackwell, Weinheim, 2012, pp. 33-64.

218. H. Hong, S. Slavov, W. Ge, F. Quian, Z. Su, H. Fang, Y. Cheng, R. Perkins, L. Shi, and W. Tong, Statistical Modelling of Molecular Descriptors, in: QSAR/QSPR, M. Dehmer, K. Varmuza, and D. Bonchev (Eds.), Wiley-Blackwell, Weinheim, 2012, pp. 65-109.

219. V. Consonni and R. Todeschini, http://www.moleculardescriptors.eu. 